\title{
Resection of adult polycystic kidney with retroperitoneal laparoscopic technique assisted by arterial embolization
}

\author{
Feng $\mathrm{Li}^{1 \#}$, Bo Li ${ }^{2 \#}$, Weijie Zhang ${ }^{1 \#}$, Yuhua Huang ${ }^{1}$, Xiaojun Zhao ${ }^{1}$, Linkun $\mathrm{Hu}^{1}$, Qilin Xi ${ }^{1}$, Qiuchen Liu ${ }^{1}$, \\ Zhijun Miao ${ }^{1}$, Jianquan $\mathrm{Hou}^{1}$, Jinxian $\mathrm{Pu}^{1}$ \\ ${ }^{1}$ Department of Urinary Surgery, First Affiliated Hospital of Soochow University, Suzhou, China; ${ }^{2}$ Department of Intervention Therapy Department, \\ First Affiliated Hospital of Soochow University, Suzhou, China \\ Contributions: (I) Conception and design: F Li, B Li; (II) Administrative support: J Pu; (III) Provision of study materials or patients: F Li, W Zhang, L \\ $\mathrm{Hu}$; (IV) Collection and assembly of data: Q Liu, Z Miao; (V) Data analysis and interpretation: F Li, B Li; (VI) Manuscript writing: All authors; (VII) \\ Final approval of manuscript: All authors. \\ \#These authors equally contributed to this work. \\ Correspondence to: Jinxian Pu. Department of Urinary Surgery, First Affiliated Hospital of Soochow University, Suzhou, China. Email: pjx62@sina.com.
}

\begin{abstract}
Background: Traditional surgical methods have high complication rate and large injury in the resection of adult polycystic kidney. We investigated the effect of retroperitoneal laparoscopic resection of adult polycystic kidney assisted by arterial embolization.

Methods: The data of adult polycystic kidney patients who underwent laparoscopic surgery assisted by arterial embolization from November 2015 to November 2018 in our hospital were retrospectively analyzed, and the data of patients who underwent open surgery during the same period were collected. The basic data, surgical conditions, postoperative recover situation, and complications of the two groups were compared.

Results: There was no significant difference in the basic situation between the laparoscopic operation group and open operation (control) group. The bleeding volume, hospitalization time, and the length of incision in the laparoscopic operation group were significantly better than those in the open operation (control) group, but the operation time was significantly longer than that in the open operation group. There was no significant difference in drainage tube extraction time, bed rest time and blood transfusion rate between the two groups. There was no significant difference in the complication rate between the two groups.
\end{abstract}

Conclusions: Arterial interventional embolization-assisted retroperitoneal laparoscopy is an effective method for the resection of polycystic kidney.

Keywords: Adult polycystic kidney; laparoscopy; intervention

Submitted Aug 24, 2020. Accepted for publication Oct 28, 2020.

doi: $10.21037 /$ tau-20-1281

View this article at: http://dx.doi.org/10.21037/tau-20-1281

\section{Introduction}

Adult polycystic kidney disease (ADPKD) is one of the most common genetic diseases in the world. It is mostly caused by the mutation of gene PKD1 (chromosome 16p) and PKD2 (chromosome 4q). This disease becomes detectable at around the age of 40 and gradually progresses to end-stage renal disease about 10 years after initial diagnosis. Globally, the incidence rate of ADPKD is around $1-2.5 \%$ (1), and about 1.5 million patients in China are afflicted with this disease (2).

Polycystic kidney disease gradually induces a variety of symptoms. Cyst enlargement and compression of the surrounding organs leads to back pain, abdominal pain, and abdominal distension, while cyst bleeding results in repeated gross hematuria and anemia. If the cyst is infected, fever and backache can also occur (1). In addition, uremia patients with polycystic kidney disease suffer a higher incidence of renal tumor than do other patients (3). At present, the treatment of polycystic kidney includes gene treatment and 
symptomatic treatment. Gene therapy has been shown to be effective, but it needs to be applied in the early stage of the disease (1). However, about $20 \%$ of patients with polycystic kidney disease need to be resected due to various complications, while other patients also require kidney resection as preparation for renal transplantation (4).

In the past, open surgery was often used to resect a polycystic kidney. With the advances in medical technology, laparoscopy has gradually replaced open surgery, as it has the advantages of using a small incision and permitting quick recovery. In recent years, use of laparoscopy has been reported in the resection of polycystic kidney resection $(5,6)$. There are two approaches of laparoscopic surgery, including transperitoneal and retroperitoneal methods. Retroperitoneal laparoscopic method is widely used in urology because of its small influence on bowel function. However, the volume of a polycystic kidney is large and the retroperitoneal room is small, which increases the difficulty of operation. In addition to this, the polycystic kidney can, on occasion, extensively adhere to the surrounding organs, which poses further challenges to retroperitoneal laparoscopic polycystic kidney resection. Our department has completed 15 cases of laparoscopic resection of polycystic kidney assisted by renal artery embolization, the results of which are described below.

We present the following article in accordance with the STROBE reporting checklist (available at http://dx.doi. org/10.21037/tau-20-1281).

\section{Methods}

\section{Clinical characteristics}

The study was performed at the First Affiliated Hospital of Soochow University, Suzhou, China. Our research was a retrospective analysis approved by the medical ethics committee of the First Affiliated Hospital of Soochow University. Written informed consent was obtained from the patient. All procedures performed in this study involving human participants were in accordance with the Declaration of Helsinki (as revised in 2013). We collected the information of the patients between November 2015 and November 2018. The inclusion criteria were that the patient was diagnosed with ADPKD according to the clinical feature and family history. The exclusion criteria included uncontrolled hypertension, other diseases requiring surgery, abnormal blood coagulation and severe cardiopulmonary dysfunction. During this period,
15 person-time accepted preoperative embolization and retroperitoneal laparoscopic resection of polycystic kidney (laparoscopic group). Meanwhile, 10 person-time accepted open operation for resection of the polycystic kidney, and served as the control group. The laparoscopic group included eight males and five females. Two male patients underwent bilateral nephrectomy by stages, and were counted as four patients. The control group consisted of nine patients. One male patient underwent bilateral nephrectomy by stages and was counted as four patients. All patients underwent abdominal CT scan before operation to evaluate the size of the polycystic kidney and its relationship with the surrounding organs (Figure 1). One patient in the laparoscopic group accepted the operation as preparation for transplantation. The other patients in the laparoscopic group and control group were resected due to severe polycystic kidney symptoms that persisted after ineffective conservative treatment.

\section{Surgical methods}

All patients underwent routine examination before operation, and those with contraindications were excluded. The contraindications included severe cardiopulmonary insufficiency, coagulation dysfunction and mental disorders. The contraindications including: patients who had been treated with regular hemodialysis were arranged with hemodialysis 1 day before operation. Bowel preparation was performed before operation. Informed consent was obtained before operation.

\section{Laparoscopic group procedure}

The patients in the laparoscopic group were treated with renal artery embolization in our interventional department 1 day before operation or on the day of operation. They were treated with analgesia and sedation before embolization. A gelatin sponge and spring coil were used for embolization (Figure 2). The patient was placed in a lateral decubitus position after general anesthesia. The surgeon and one assistant stood at the dorsal side of the patient. Another assistant stood at the ventral side of the patient. Monitors were located at the head of the operating table. The first hole (A point, Figure $3 A$ ) was built near axillary midline under the $12^{\text {th }}$ costal margin. Forceps were used to separate into the posterior abdominal cavity. Then, the surgeon used a finger to free the cavity. A balloon was inserted into the cavity and injected with $500 \mathrm{~mL}$ of air. Under the guidance of fingers, a $12-\mathrm{mm}$ trocar was punctured 

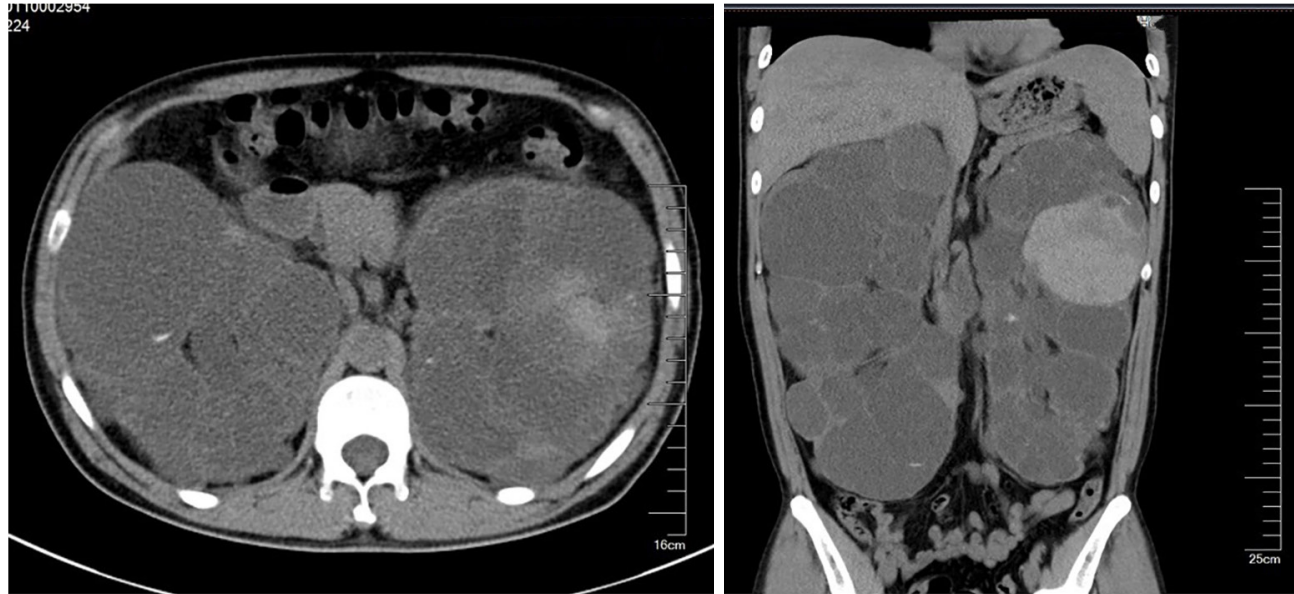

Figure 1 A computed tomography scan of an ADPKD patient before operation.
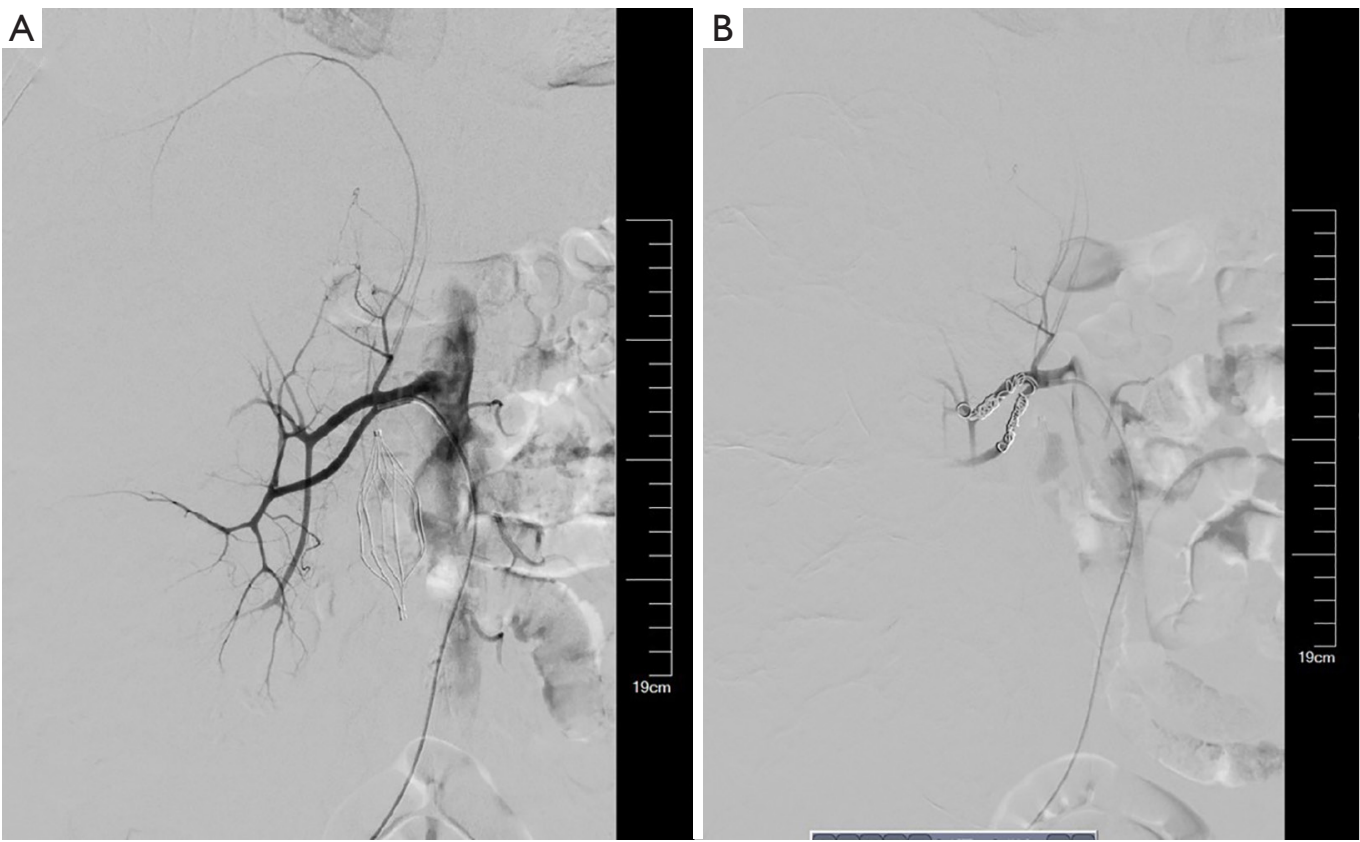

Figure 2 The renal arteriography of an ADPKD patient. (A) The image before embolization. We can see the patient's renal artery has two branches; (B) the image after embolization. After embolization by gelatin sponge and spring coil, the blood supply to the kidney noticeably worsened.

at the level of the iliac spine in the anterior axillary line to act as an observation hole (C point, Figure $3 A$ ). Next, carbon dioxide was injected into the retroperitoneal space through the observation hole. The first hole was the main operation port, and a $12-\mathrm{mm}$ trocar was inserted. A $5 \mathrm{~mm}$ trocar was punctured between the main operation port and the observation hole (B point, Figure 3A). Another
$12 \mathrm{~mm}$ trocar was punctured near the tip of the 11th rib in the anterior axillary line (D point, Figure $3 A$ ). The psoas major muscle was located, and the perirenal fascia was opened. If the space was too small, part of the cyst could be decorticated. If it was difficult to expose the pedicle, we cut through the middle of the kidney. We could then handle the renal pedicle. After lengthening the incision, the 

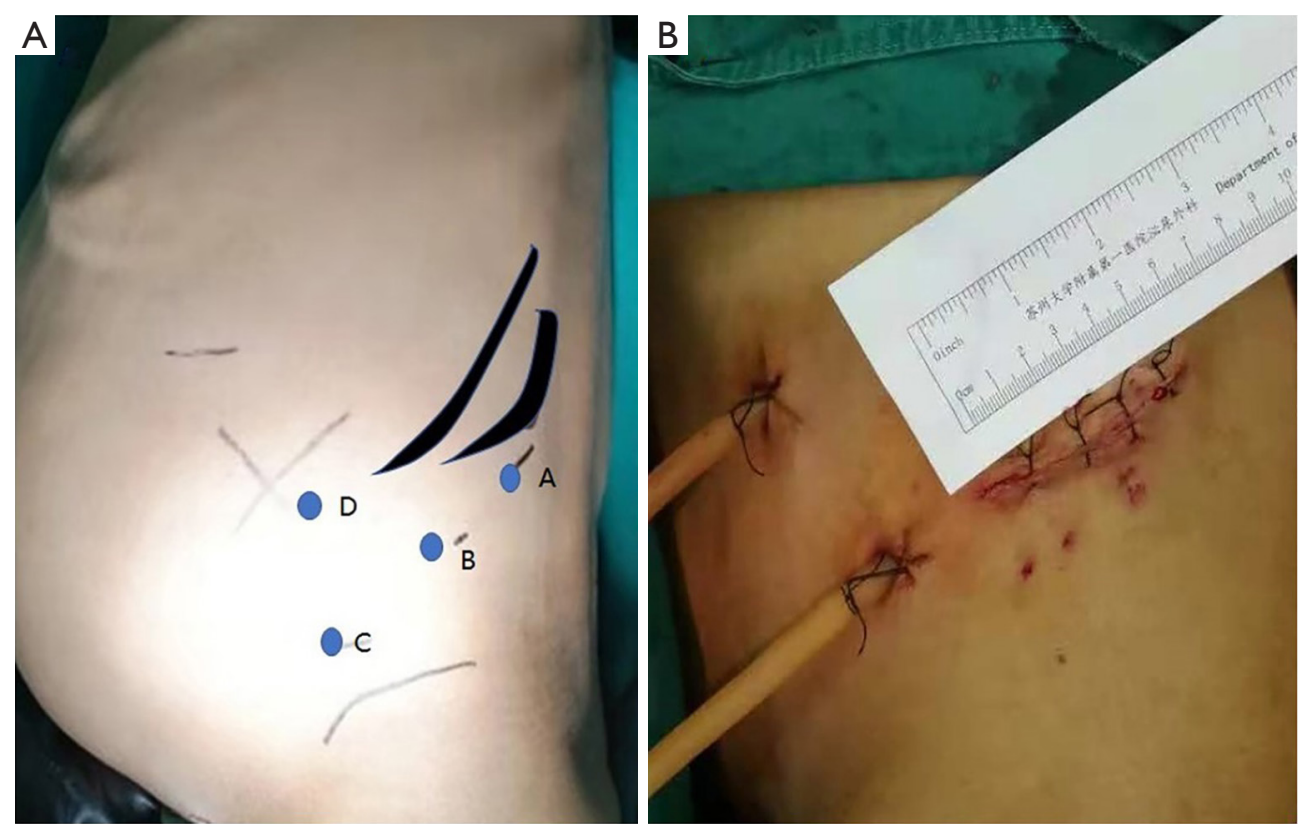

Figure 3 The pictures of a patient in the laparoscopic group. (A) The posture and trocar position of the operation; (B) the incision in the laparoscopic group after operation.

specimen was taken out in pieces, and the drainage tube was indwelled.

\section{Control group procedure}

The patient was placed in a lateral decubitus position after general anesthesia. The skin, subcutaneous tissue, and muscular layer were incised layer by layer through a $12^{\text {th }}$ rib oblique incision, and the perirenal fascia was opened. The kidney was freed, and the renal pedicle was exposed. The renal pedicle and ureter were then ligated. At last, the kidney was completely removed.

\section{Statistical analysis}

Spss19.0 statistical software was used to analyze the data. Chi square test was used for counting data, and Fisher's exact probability was calculated. T-test was used for measurement data, and the difference was statistically significant with $\mathrm{P}<0.05$.

\section{Results}

\section{Clinical feature}

The general information of the patients in this study is summarized in Table 1. There were 13 patients in the laparoscopic group, including 8 males and 5 females, with an average age of 43.7 years (33-66 years). There were 9 patients in the open group, including 7 males and 2 females, with an average age of 46.1 years (21-62 years).

The size of the operated kidney in the two groups was estimated using the maximum diameter line and volume of the polycystic kidney. The maximum diameter line was measured by preoperative CT. The volume was calculated using the following formula: volume $=$ upper and lower diameter line $x$ left and right diameter line $\mathrm{z}$ anteroposterior diameter line $\times \pi / 6$ (7). The average maximum diameter of the patients in the laparoscopic group was $246.3 \mathrm{~mm}$, and the average volume of the polycystic kidney was $2,375.9 \mathrm{~cm}^{3}$. The average maximum diameter of the open group was $193.5 \mathrm{~mm}$, and the average volume of the polycystic kidney was $1,957.0 \mathrm{~cm}^{3}$. The maximum diameter of kidney in the laparoscopic group was longer than that in the open group $(\mathrm{P}=0.046)$, but there was no significant difference in the mean volume of the polycystic kidney between the two groups. The average body mass index (BMI) of the open group was 21.9, while that of the laparoscopic group was 20.0, which was not a significant difference $(\mathrm{P}=0.271)$.

Three patients in the control group had a history of abdominal surgery, while two patients in the laparoscopic group had a history of abdominal surgery, which was not a significant difference. Seven patients in the control group 
Table 1 Baseline clinical characteristics between the control group and the laparoscopic group

\begin{tabular}{|c|c|c|c|}
\hline Item & Control group & $\begin{array}{l}\text { Laparoscopic } \\
\text { group }\end{array}$ & $\mathrm{P}$ \\
\hline Operation number & 10 & 15 & - \\
\hline Patient number & 9 & 13 & - \\
\hline Male (\%) & 7 (77.8) & $8(61.5 \%)$ & 0.659 \\
\hline Age (years) & $43.7 \pm 11$ & $46.1 \pm 9.5$ & 0.573 \\
\hline $\mathrm{BMI}$ & $21.9 \pm 1.6$ & $20.0 \pm 3.7$ & 0.271 \\
\hline $\begin{array}{l}\text { Maximum diameter } \\
\text { line }\end{array}$ & $193.5 \pm 48.1$ & $246.3 \pm 68.7$ & $0.046^{\star}$ \\
\hline Volume of kidney & $1,957.0 \pm 966.3$ & $2,375.9 \pm 1,553.0$ & 0.456 \\
\hline $\begin{array}{l}\text { Rate of abdominal } \\
\text { surgery history }\end{array}$ & $3 / 9$ & $2 / 13$ & 0.358 \\
\hline Rate of dialysis & $7 / 9$ & $11 / 13$ & 0.358 \\
\hline \multicolumn{4}{|l|}{ Indication } \\
\hline $\begin{array}{l}\text { Abdominal } \\
\text { distention }\end{array}$ & 1 & 5 & 0.345 \\
\hline Hematuria & 6 & 6 & 0.226 \\
\hline Backache & 2 & 2 & 1.000 \\
\hline Infection & 0 & 1 & 1.000 \\
\hline $\begin{array}{l}\text { Hemoglobin before } \\
\text { operation }\end{array}$ & $112.8 \pm 32.6$ & $91.5 \pm 22.7$ & 0.065 \\
\hline $\begin{array}{l}\text { Resection side (left } \\
\text { right) }\end{array}$ & $5 / 5$ & $8 / 7$ & 1.00 \\
\hline $\begin{array}{l}\text { Preoperative } \\
\text { creatinine level }\end{array}$ & $718.7 \pm 397.8$ & $771.3 \pm 311.7$ & 0.714 \\
\hline
\end{tabular}

Table 2 Perioperative condition between the control group and the laparoscopic group

\begin{tabular}{lccc}
\hline Item & Control group & $\begin{array}{c}\text { Laparoscopic } \\
\text { group }\end{array}$ & $\mathrm{P}$ \\
\hline Blood loss $(\mathrm{mL})$ & $210.5 \pm 81.9$ & $121.3 \pm 63.3$ & $0.01^{*}$ \\
Operation time (hours) & $2.4 \pm 0.5$ & $3.8 \pm 1.4$ & $0.002^{\star}$ \\
Length of incision (cm) & $17.5 \pm 1.8$ & $9.3 \pm 2.8$ & $0.000^{*}$ \\
Drainage tube extraction & $10.7 \pm 10.4$ & $7.5 \pm 6.0$ & 0.332 \\
time (days) & & & \\
Bed rest time (days) & $5.2 \pm 1.2$ & $4.6 \pm 0.8$ & 0.157 \\
Hospitalization time (days) & $20 \pm 3.5$ & $16.1 \pm 2.4$ & $0.003^{*}$ \\
Blood transfusion rate (\%) & $60.0 \%(6 / 10)$ & $33.3 \%(5 / 15)$ & 0.241 \\
\hline${ }^{*}, \mathrm{P}<0.05$. & & &
\end{tabular}

received regular dialysis before operation, and eleven patients in the laparoscopic group received regular dialysis, which was not a significant difference. In the control group, reasons for removing the polycystic kidney included abdominal distension in one patient, repeated hematuria in six patients, and low back pain in two patients. In the laparoscopic group, reasons for removing the polycystic kidney included abdominal distension in four patients, repeated hematuria in six patients, low back pain in two patients, repeated fever due to cyst infection in one patient, and preparation of renal transplantation in one patient. The mean preoperative hemoglobin of the open group was $112.8 \mathrm{~g} / \mathrm{L}$, and that of the laparoscopic group was $91.5 \mathrm{~g} / \mathrm{L}$, which was not a significant difference. The average creatinine of patients in the open group was $718.7 \mu \mathrm{mol} / \mathrm{L}$, and that of the laparoscopic group was $771.3 \mu \mathrm{mol} / \mathrm{L}$, which was not a significant difference.

\section{Comparison of perioperative conditions}

The perioperative situation of the two groups is shown in Table 2. The average intraoperative blood loss in the control group was $210.5 \mathrm{~mL}$, while that in the laparoscopic group was $121.3 \mathrm{~mL}$, which was significantly lower $(\mathrm{P}=0.01)$. The operation time of the control group was 2.4 hours, while that of the laparoscopic group was 3.8 hours. The operation time of the laparoscopic group was significantly longer than that of the control group $(\mathrm{P}=0.002)$. The average incision length of the control group was $17.5 \mathrm{~cm}$, and that of the laparoscopic group was $9.3 \mathrm{~cm}$ (Figure 3B). The incision length of the patients in the laparoscopic group was significantly shorter $(\mathrm{P}<0.001)$. The average hospitalization time of the control group was 20.0 days, and the average hospitalization time of the laparoscopic group was 16.1 days. The hospitalization time of the control group was significantly longer than that of the endoscopic group $(\mathrm{P}=0.003)$. There was no significant difference between the two groups in the drainage tube extraction time, postoperative bed rest time, or intraoperative blood transfusion rate.

\section{Comparison of complications after operation}

The incidence of postoperative complications in the two groups is listed in Table 3. The postoperative complications were defined according to the Clavien classification (8). There were 20 person-time G1 grade complications in the laparoscopic group, 15 person-time G1 grade complications 
Table 3 The complications of the control group and the laparoscopic group

\begin{tabular}{lccc}
\hline Type of complication & Control group & $\begin{array}{c}\text { Laparoscopic } \\
\text { group }\end{array}$ & P \\
\hline G1 & 6 & 8 & 1.00 \\
Vomiting & 7 & 10 & 1.00 \\
Wound pain & 2 & 2 & 1.00 \\
Lymphatic leakage & & & \\
G2 & 6 & 5 & 0.24 \\
Blood transfusion & 2 & 3 & 1.00 \\
Fever & 3 & 1 & 0.267 \\
Incomplete intestinal & & & \\
obstruction & & 1 & 0.543 \\
G3a & 2 & & \\
Delayed wound healing & & & \\
\hline
\end{tabular}

in the control group, and the incidence between the groups was not significantly different $(\mathrm{P}>0.05)$. The main G1 complications were vomiting, wound pain, and lymphatic leakage. The main G2 complications were blood transfusion, fever, and incomplete intestinal obstruction, but the differences in complication type were not significant $(\mathrm{P}>0.05)$. The main G3 complication was delayed wound healing, and there was no significant difference between the two groups $(\mathrm{P}>0.05)$.

\section{Discussion}

Polycystic kidney patients show no obvious symptoms in the early stage, and most patients are first diagnosed by physical examination. The indications for resection of the diseased kidney mainly include unbearable pain, relief of organ compression, or the provision of space for kidney transplantation (5). In the past, open surgery was the standard method for the removal of a polycystic kidney. Recently, some experts have begun to report on laparoscopic resection of the polycystic kidney $(5,6)$. The polycystic kidney that needs surgery is usually large in volume and repeatedly inflamed. Thus, the kidney is usually close to the surrounding tissues, leaving very little space for the operator. Therefore, laparoscopic resection of polycystic kidney is often more challenging, and the risk of complications is also relatively high. For instance, Gregory's research reported a complication rate of $33 \%$ for a laparoscopic surgery group (5). Vascular-related complications accounted for the vast majority of these complications, and included hemorrhage and arteriovenous fistula. If these vascular-related complications can be solved, the laparoscopic technique will be a better choice for polycystic kidney resection. Our center has attempted to first to embolize the renal artery before operation to reduce the perioperative vascular complications.

This study compared the two methods and found that the intraoperative blood loss in the laparoscopic group was significantly lower than that in the control group, while the rate of vascular complication was lower than that reported in another study (5). The advantage of our method is the pretreatment of the renal vessel. The embolization of the renal artery can reduce intraoperative bleeding, leaving the visual field of the operation clear and facilitating the exact management of the renal pedicle. The difficulty of retroperitoneal laparoscopic surgery for a polycystic kidney also includes the large volume of the polycystic kidney, the small retroperitoneal space, and the difficulty of exposing the renal pedicle. After renal artery embolization before operation, we can decorticate the renal cyst or even cut the kidney to reduce the volume of the kidney with a low risk of bleeding. Another advantage of this method is that it reduces the size of the large specimen, making it easier to remove, thus requiring a smaller incision.

Some studies have reported on the treatment of a polycystic kidney by renal artery embolization alone $(9,10)$. This method can reduce the volume of the polycystic kidney, but a possibility of recurrence and ischemic pain after embolization remains. The effect of renal artery embolization alone in the treatment of polycystic kidney is not exact and the side effects are significant. In order to reduce ischemic pain after embolization in our unit, we embolize the renal artery the day before the operation or in the morning of the operation day to shorten the time between embolization and operation.

In the past, the key point of laparoscopic nephrectomy has been the handling of the renal pedicle. Some experts advocated that the position of the observation port and main operation port should be close to the dorsal side (11). However, this can make managing the ventral side challenging, as it is easy to break the peritoneum. In our approach, there is no concern over bleeding due to the embolization of the renal artery. We can select the trocar position on the ventral side. When managing the renal pedicle, we can first remove the renal cyst or even part of the kidney, which conveniently exposes the renal 
vessels, and we can also more easily manage the ventral side. Compared with the transabdominal approach, the retroperitoneal approach has less impact on abdominal organs. The patients' bowel function could recover faster after operation and the patients had lower probability of bowel related complications.

The present study compared the incidence of postoperative complications between a laparoscopic and open surgery (control) group. There was no significant difference in the probability of the various postoperative complications between the two groups. The incidence of postoperative wound pain was lower in the laparoscopic group by virtue of the small incision. The drainage tube extraction time and ambulation time of patients in the postoperative laparoscopic group were both longer than those of the open surgery group, although the difference was not statistically significant. These longer durations observed may be due to the small number of cases studied.

Our study showed that retroperitoneal laparoscopic technique assisted by arterial embolization is a good method to resect polycystic kidney. It has the advantages of less bleeding and faster recovery. However, it still entails a few disadvantages, including a long operation time, along with high cost and skill requirements for the operator. These drawbacks can be overcome through an improvement of the medical insurance system and the further development of medical technology. Ultimately, retroperitoneal laparoscopy combined with interventional embolization is an effective way to resect the polycystic kidney.

\section{Acknowledgments}

Funding: None.

\section{Footnote}

Reporting Checklist: The authors have completed the STROBE reporting checklist. Available at http://dx.doi. org/10.21037/tau-20-1281

Data Sharing Statement: Available at http://dx.doi. org/10.21037/tau-20-1281

Conflicts of Interest: All authors have completed the ICMJE uniform disclosure form (available at http://dx.doi. org/10.21037/tau-20-1281). The authors have no conflicts of interest to declare.
Ethical Statement: The authors are accountable for all aspects of the work in ensuring that questions related to the accuracy or integrity of any part of the work are appropriately investigated and resolved. The research was a retrospective analysis approved by the medical ethics committee of the First Affiliated Hospital of Soochow University. Written informed consent was obtained from the patient. All procedures performed in this study involving human participants were in accordance with the Declaration of Helsinki (as revised in 2013).

Open Access Statement: This is an Open Access article distributed in accordance with the Creative Commons Attribution-NonCommercial-NoDerivs 4.0 International License (CC BY-NC-ND 4.0), which permits the noncommercial replication and distribution of the article with the strict proviso that no changes or edits are made and the original work is properly cited (including links to both the formal publication through the relevant DOI and the license). See: https://creativecommons.org/licenses/by-nc-nd/4.0/.

\section{References}

1. Bergmann C, Guay-Woodford LM, Harris PC, et al. Polycystic kidney disease. Nat Rev Dis Primers 2018;4:50.

2. Dai B, Mei CL. Research on autosomal dominant polycystic kidney disease in China. Chin Med J (Engl) 2006;119:1915-24.

3. Hajj P, Ferlicot S, Massoud W, et al. Prevalence of renal cell carcinoma in patients with autosomal dominant polycystic kidney disease and chronic renal failure. Urology 2009;74:631-4.

4. Chen K, Tan YG, Tan D, et al. Predictors and outcomes of laparoscopic nephrectomy in autosomal dominant polycystic kidney disease. Investig Clin Urol 2018;59:238-45.

5. Verhoest G, Delreux A, Mathieu R, et al. Transperitoneal laparoscopic nephrectomy for autosomal dominant polycystic kidney disease. JSLS 2012;16:437-42.

6. Guo P, Xu W, Li H, et al. Laparoscopic nephrectomy versus open nephrectomy for patients with autosomal dominant polycystic kidney disease: a systematic review and meta-analysis. PLoS One 2015;10:e129317.

7. Breau RH, Clark E, Bruner B, et al. A simple method to estimate renal volume from computed tomography. Can Urol Assoc J 2013;7:189-92.

8. Dindo D, Demartines N, Clavien PA. Classification of 
surgical complications: a new proposal with evaluation in a cohort of 6336 patients and results of a survey. Ann Surg 2004;240:205-13.

9. Yamagami T, Kajiwara K, Yamanishi T, et al. Use of a micro-balloon catheter in transcatheter arterial embolization of the renal artery for recurrence of symptoms of autosomal dominant polycystic kidney disease. Acta Radiol Open 2018;7:2058460118818849.

10. Rim H, Jung GS, Jung YS. Transcatheter arterial embolization using ethanol in a dialysis patient for contracting enlarged polycystic kidneys. Korean J Radiol 2010;11:574-8.

11. Benoit T, Peyronnet B, Roumiguié M, et al. Laparoscopic nephrectomy for polycystic kidney: comparison of the transperitoneal and retroperitoneal approaches. World J Urol 2016;34:901-6.

(English Language Editor: J. Gray)
Cite this article as: $\mathrm{Li} \mathrm{F,} \mathrm{Li} \mathrm{B,} \mathrm{Zhang} \mathrm{W,} \mathrm{Huang} \mathrm{Y,} \mathrm{Zhao}$ X, Hu L, Xi Q, Liu Q, Miao Z, Hou J, Pu J. Resection of adult polycystic kidney with retroperitoneal laparoscopic technique assisted by arterial embolization. Transl Androl Urol 2020;9(6):2705-2712. doi: 10.21037/tau-20-1281 